\title{
Editorial: Virtual Philosophy
}

We hear a lot these days about distance learning, about tutorials by e-mail and about universities on the internet. The idea in each case is that the student works at his or her computer and does not have to travel to a university or actually meet real tutors and professors in the flesh. There may be tutors and professors involved, but they will be transmitted in electronic form, through lectures beamed up and downloaded, and through tutorials wafting back and forth in cyber-space.

To some extent these ideas may be a response to problems arising from the over-expansion of existing (physical) universities. There are too many students and too few good staff. So sharing staff around via the internet would give more students access to good lectures and tutorials, while at the same time (possibly) giving dons more time for their own scholarship.

An initial reaction to such a prospect might be that internet contact between philosophers and students is better than no contact at all. But there would still be a feeling among many that it would be at best a substitute for the real thing. Is this feeling right, though?

After all, it might be said, philosophy is above all discussion of abstract ideas in the abstract. Might philosophy not lend itself particularly to discussion which is not just abstract, but disembodied too? In philosophy at least, virtual tutorials need not be just a substitute for real tutorials. They might actually be better. For they would be conducted without any of the distractions of physical reality and of appearance and of the sheer contingency which in the real world interfere with the unhindered development of pure thought.

This, though, overlooks the importance in any genuine education of encounters between real teachers and real students. We have all had the experience of reading something in a book, and being initially convince by it, only to be dissuaded from its truth when we have actually had to expound or defend it in person. Part of what is involved in what Leavis used to call the 'collaborative-creative process' of university level discussion, a process at once critical and constructive, is personal identification with what one is saying or thinking, and the testing of this identification against other people equally personally involved in the dialogue. It is I who am identifying myself with this view, and staking myself on it, I, the whole person, and not some disembodied phantasm involved in an irresponsible simulacrum of communication and with some other equally doi:10.1017/S0031819104000014

(C)2004 The Royal Institute of Philosophy

Philosophy 792004 


\section{Editorial}

disembodied phantasm, we know not where. We do not need to reflect on the conundra of the Chinese room here; the all too wellknown inconveniences and fantasizing of chat rooms should be enough to warn us off the idea of a purely 'virtual' tutorial. We forget, at our peril, that a thinker, at least the sort of thinker we might hope emerges from a philosophical education, is and has to be a person, with all that that involves in terms of integrity, consistency and development of character.

Postal and e-mail tutorials may be better than none at all, but they are at best substitutes for real meetings between real students and real tutors. Some may find it moot whether it might not be better to have an internet lecture or e-mail tutorial from some charismatic and telegenic star of the screen than to meet dull old Dr Smith of The University of the Balls Pond Road, but assuming that Smith has any knowledge or life in him at all, once the initial excitement is over, there is really no comparison at all. Even if a student receives as detailed a set of comments on an essay as could be imagined (a big if, one imagines, in most cases), written comments are only the start of a real tutorial. The student needs to be able to discuss these comments in the light of his or her actual understanding, and the tutor needs to be able to expand and qualify what he or she has written in the light of the student's living reactions. Nor, for similar reasons is there any substitute for a student building up a real relation with a real tutor, which is all but impossible without real and frequent contact.

And apart from formal encounters with one's teachers, a crucial part of a university education is one's informal encounters with one's peers. In such encounters young people discuss with each other all manner of questions, philosophical, cultural, scientific, political, moral and personal, related and unrelated to their formal studies. Those who talk of virtual universities forget that education, if it is real education, is education of the whole person, in which the whole person is engaged both inside and outside formal sessions. It is vital to remember this above all in the case of philosophical education, where the abstractness of the subject can too easily lead us to forget its ultimate point. 